\title{
The protective effect of geniposide on human neuroblastoma cells in the presence of formaldehyde
}

Ping Sun ${ }^{1 \dagger}$, Jin-yan Chen ${ }^{3 \dagger}$, Jiao Li ${ }^{1}$, Meng-ru Sun ${ }^{3}$, Wei-chuan Mo ${ }^{2}$, Kai-li Liư ${ }^{2}$, Yan-yan Meng ${ }^{1}$, Ying Liư ${ }^{2}$, Feng Wang ${ }^{1}$, Rong-qiao $\mathrm{He}^{2^{*}}$ and Qian Hua ${ }^{{ }^{*}}$

\begin{abstract}
Background: Formaldehyde can induce misfolding and aggregation of Tau protein and $\beta$ amyloid protein, which are characteristic pathological features of Alzheimer's disease (AD). An increase in endogenous formaldehyde concentration in the brain is closely related to dementia in aging people. Therefore, the discovery of effective drugs to counteract the adverse impact of formaldehyde on neuronal cells is beneficial for the development of appropriate treatments for age-associated cognitive decline.

Methods: In this study, we assessed the neuroprotective properties of TongLuoJiuNao (TLJN), a traditional Chinese medicine preparation, against formaldehyde stress in human neuroblastoma cells (SH-SY5Y cell line). The effect of TLJN and its main ingredients (geniposide and ginsenoside Rg1) on cell viability, apoptosis, intracellular antioxidant activity and the expression of apoptotic-related genes in the presence of formaldehyde were monitored.

Results: Cell counting studies showed that in the presence of TLN, the viability of formaldehyde-treated SH-SY5Y cells significantly recovered. Laser scanning confocal microscopy revealed that the morphology of formaldehyde-injured cells was rescued by TLN and geniposide, an effective ingredient of TLN. Moreover, the inhibitory effect of geniposide on formaldehyde-induced apoptosis was dose-dependent. The activity of intracellular antioxidants (superoxide dismutase and glutathione peroxidase) increased, as did mRNA and protein levels of the antiapoptotic gene BCl-2 after the addition of geniposide. In contrast, the expression of the apoptotic-related gene - P53, apoptotic executer - caspase 3 and apoptotic initiator - caspase 9 were downregulated after geniposide treatment.
\end{abstract}

Conclusions: Our results indicate that geniposide can protect SH-SY5Y cells against formaldehyde stress through modulating the expression of $\mathrm{BCl}-2$, P53, caspase 3 and caspase 9, and by increasing the activity of intracellular superoxide dismutase and glutathione peroxidase.

Keywords: Formaldehyde impairment, Geniposide, Neuroprotection

\section{Background}

Reactive aldehydes are generated by several endogenous and exogenous processes in biological systems. They target cell membranes, induce lipid peroxidation, mitochondrial dysfunction and oxidative stress, and eventually lead to cell

\footnotetext{
*Correspondence: herq@sun5.ibp.ac.cn; hqianz@aliyun.com

${ }^{\dagger}$ Equal contributors

${ }^{2}$ State Key Laboratory of Brain and Cognitive Science, Institute of Biophysics, Chinese Academy of Sciences, 15 Datun Road, Chaoyang District, Beijing 100101, China

'School of Preclinical Medicine, Beijing University of Chinese Medicine, 11 Bei San Huan Dong Road, Chaoyang District, Beijing 100029, China

Full list of author information is available at the end of the article
}

apoptosis [1]. Reactive aldehydes are associated with the etiology of several neurological and psychiatric disorders including chronic alcohol abuse, vascular dementia and Alzheimer's disease (AD) [2-4].

Formaldehyde is one of the reactive aldehydes with important clinical implications. He et al. summarized that formaldehyde can influence nerve function and that it is linked to the development of psychiatric disorders [5]. An epidemiological study has shown that histology technicians and workers who are chronically exposed to formaldehyde exhibit a marked decline in cognitive ability [6]. Formaldehyde concentrations in the hippocampus and

\section{Biomed Central}


urine of $\mathrm{AD}$ patients are significantly higher than those of healthy aged individuals [7]. The activity of mitochondrial aldehyde dehydrogenases, the main metabolic enzyme of formaldehyde, is significantly increased in the putamen of $\mathrm{AD}$ patients [1]. Furthermore, formaldehyde induces the hyperphosphorylation and aggregation of neuronal Tau protein [8] and aggregation of Tau protein in vitro and in vivo [9-11]. These misfolded amorphous deposits are able to induce apoptosis of human neuroblastoma cells (SH-SY5Y cell line) and primary rat hippocampal cells [9]. Formaldehyde can also promote the misfolding, oligomerization, and fibrillogenesis of $\beta$ amyloid protein (A $\beta$ ) [12]. Therefore, formaldehyde is closely related to age-associated dementia. Recently, the discovery of effective drugs to counteract the adverse impacts of formaldehyde on the central nervous system and promoting the survival of neuronal cells, has become of great interest to many neuropharmacologists.

TongLuoJiuNao (TLJN), a traditional Chinese medicine (TCM), is clinically efficacious in the treatment of ischemic cerebral stroke and dementia (Chinese SFDA: 2004 L01620). It has been reported that TLJN can protect brain tissue against ischemia after the induction of middle cerebral artery occlusion in rats, by reducing not only infarct volume but also penumbra size [13], and alleviate the damage to ischemia/reperfusion-injured neurons [14]. Moreover, TLJN can improve learning and memory ability, promote the degradation of $A \beta$, and clear amyloid plaques from the AD rat brain [15]. The main ingredients of TLJN are geniposide and ginsenoside Rg1 [14]. Ginsenoside Rg1 has neuroprotective effects in mesencephalic dopaminergic cells stressed with glutamate [16], while geniposide can protect PC12 cells from hydrogen peroxide-induced cell death via its involvement in the PI3K signaling pathway and its ability to activate the glucagon-like peptide 1 receptor (GLP-1R) [15]. Geniposide is also able to regulate insulin secretion through activating GLP-1R [16]. Thus, TLJN (geniposide and ginsenoside Rg1) is likely to be an appropriate drug for the treatment of dementia. However, whether it has any protective effects on reactive aldehydetreated neuronal cells, in particular formaldehyde-stressed neurons, remains unclear.

Direct addition of formaldehyde to the cell culture medium is a common cell culture model used in studies on aldehyde toxicity [15]. Here, we examined the neuroprotective effects of TLJN and its main ingredients, geniposide and ginsenoside Rg1, on formaldehyde-stressed SH-SY5Y cells.

\section{Methods}

\section{Materials}

TLJN was provided by Kangyuan Pharmaceutical Engineering Co. Ltd (Beijing, China). The concentrations of geniposide $(4.95 \mathrm{mg} / \mathrm{mL})$ and ginsenoside Rg1 (1.02 mg/mL) in TLJN were determined by high performance liquid chromatography (HPLC; Figure 1) [14]. The purified geniposide and ginsenoside Rg1 were from the National Institutes for Food and Drug Control (Beijing, China). The cell counting Kit-8 (CCK-8) for measurement of cell viability was from Dojindo Co. (Kumamoto, Japan). Hoechst33258 was from Sigma and Alexa Fluor 488 Phalloidin was from Invitrogen (Carlsbad, CA, USA). The primary antibody against Bcl-2 was purchased from Cell Signaling Technology (Waltham, MA, USA) and the $\beta$-actin antibody was from Beyotime Institute of Biotechnology (Jiangsu, China). The enhanced chemiluminescence (ECL) substrate was from Pierce (Boston, MA, USA) and polyvinylidene difluoride (PVDF) membrane was purchased from Millipore (Billerica, MA, USA). The annexin $\mathrm{V}$ apoptosis detection kit, total superoxide dismutase (SOD) assay kit with WST-1, cellular glutathione peroxidase (GSHPx) assay kit and catalase assay kit were from the Beyotime Institute of Biotechnology (Jiangsu, China). The Taq DNA Polymerase and TansStartTM Green qPCR SuperMix were purchased from Transgen Inc. (Beijing, China). The primers for Bcl-2, P53, caspase 3, caspase 9, $\beta$-actin and $18 s$ RNA were designed and synthesized by Shanghai Sangon Biotech Co. Ltd (Shanghai, China).

\section{Cell culture}

SH-SY5Y cells were grown in Dulbecco's modified eagle medium (DMEM) containing 10\% (v/v) fetal bovine serum (Invitrogen) and maintained in 5\% (v/v) $\mathrm{CO}_{2} / 90 \%(\mathrm{v} / \mathrm{v})$ humid air at $37^{\circ} \mathrm{C}$. Cells were plated onto 96 -well culture plates at a density of $1 \times 10^{4}$ cells/well for cytotoxicity assays or $60-\mathrm{mm}$ culture dishes at a density of $1 \times 10^{6}$ cells/ well for western blotting, RT-PCR, flow cytometry, and total SOD detection. After $24 \mathrm{~h}$, the culture medium was replaced with serum-free DMEM supplemented with $0.12 \mathrm{mM}$ formaldehyde, and different concentrations of drugs were used to treat cells as indicated in the results.

\section{Cell viability assay}

The viability of cells was evaluated using the CCK-8 kit. Briefly, $10 \mu \mathrm{L}$ of the CCK- 8 solution was added to each well of the 96 -well plate and left to incubate for $4 \mathrm{~h}$ in the incubator at $37^{\circ} \mathrm{C}$. According to the manufacturer, simultaneous absorbance readings were measured at 450 and $630 \mathrm{~nm}$ using a microplate reader. The difference between the two readings was used in the final analysis.

\section{Cell morphology analysis}

SH-SY5Y cells (plated at $3 \times 10^{5}$ ) were grown in DMEM containing $10 \%(\mathrm{v} / \mathrm{v})$ fetal bovine serum in $5 \%(\mathrm{v} / \mathrm{v})$ $\mathrm{CO}_{2} / 90 \%$ (v/v) humid air at $37^{\circ} \mathrm{C}$. After $12 \mathrm{~h}$ of plating, the culture medium was replaced with serum-free DMEM in the presence of $0.12 \mathrm{mM}$ formaldehyde 

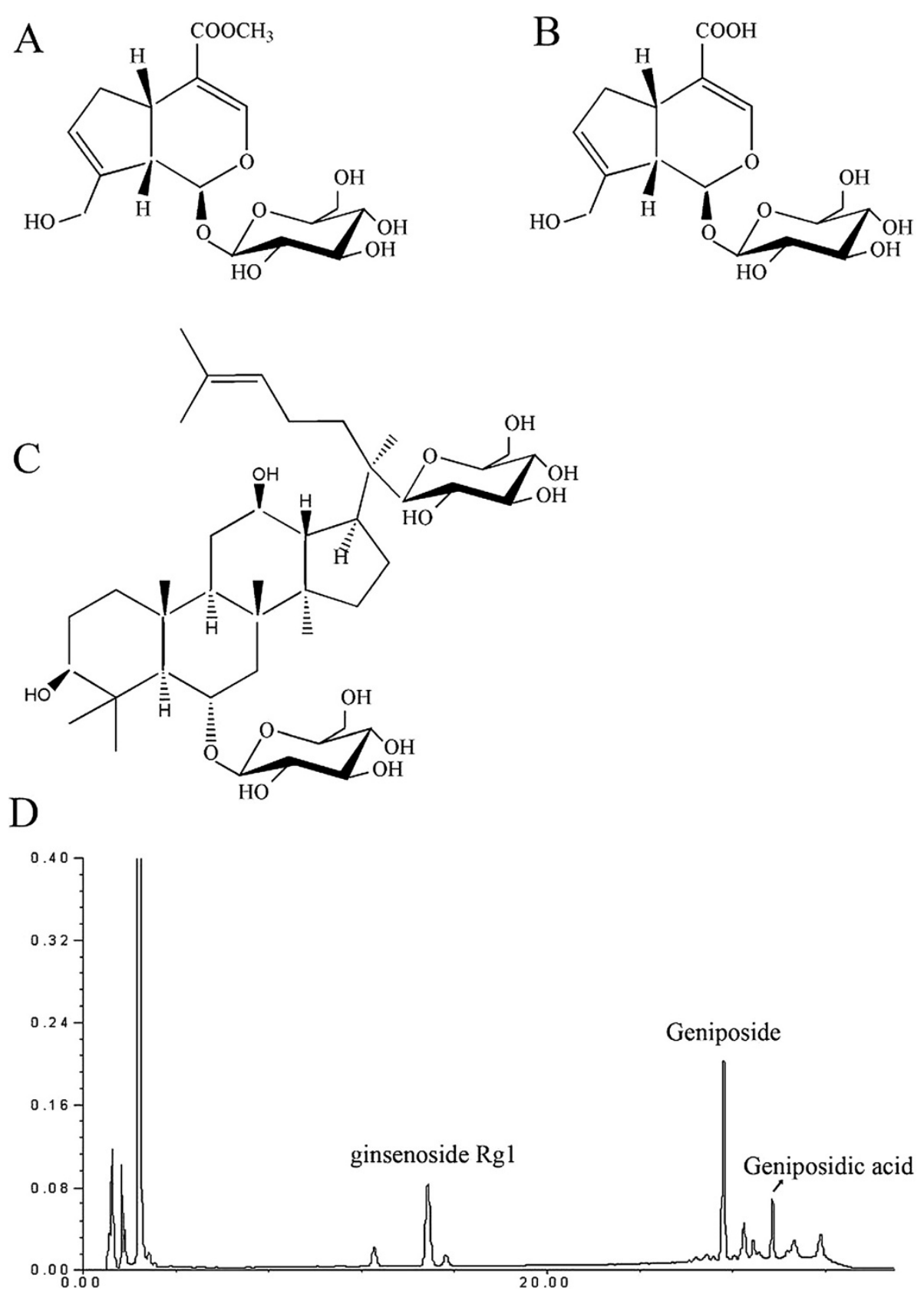

Figure 1 Chemical structures and HPLC analysis of TLN. A. Geniposide $\left(\mathrm{C}_{16} \mathrm{H}_{24} \mathrm{O}_{10}\right.$, molecular weight $\left.388 \mathrm{Da}\right) ; \mathbf{B}$. Geniposidic acid $\left(\mathrm{C}_{16} \mathrm{H}_{22} \mathrm{O}_{10}\right.$, molecular weight $374 \mathrm{Da}) ; \mathbf{C}$. Ginsenoside $\mathrm{Rg} 1\left(\mathrm{C}_{42} \mathrm{H}_{72} \mathrm{O}_{14}\right.$, molecular weight $\left.800 \mathrm{Da}\right) ; \mathbf{D}$. HPLC analysis of TLN.

supplemented with $100 \mu \mathrm{M}$ geniposide, $10 \mu \mathrm{M}$ ginsenoside Rg1 or TLJN, which consisted of $100 \mu \mathrm{M}$ geniposide and $10 \mu \mathrm{M}$ ginsenoside Rg1. At different time intervals $(6,12$, and $24 \mathrm{~h})$, cells were fixed with $4 \%(\mathrm{w} / \mathrm{v})$ paraformaldehyde. Hoechst33258 was applied to label the nuclei and F-actin was labeled with phalloidin. All images were obtained by laser scanning confocal microscopy (LSCM; Olympus FV1000, Tokyo, Japan).

\section{Analysis of apoptosis}

Analysis of apoptosis was carried out by flow cytometry using the annexin $\mathrm{V}$ apoptosis detection kit. Cells were harvested, counted, and resuspended in $1 \mathrm{x}$ binding buffer at a concentration of $1 \times 10^{6}$ cells $/ \mathrm{mL}$. The cell suspension $(100 \mu \mathrm{L})$ was transferred to a $5 \mathrm{~mL}$ culture tube and $5 \mu \mathrm{L}$ of Annexin V-FITC was added. The suspension was gently mixed and incubated for $10 \mathrm{~min}$ at room temperature in the dark. Propidium iodide (PI) 
was added $(10 \mu \mathrm{L})$ and samples were analyzed by flow cytometry (FACSCalibur, BD Biosciences, San Jose, CA, USA) within $1 \mathrm{~h}$.

\section{Western blotting}

Western blotting was carried out as previously described [17]. SH-SY5Y cell lysates were prepared and $50 \mu \mathrm{g}$ of protein was loaded on a $12 \%(w / v)$ sodium dodecylsulfate-polyacrylamide gel. The separated proteins were transferred to PVDF membrane and the membrane was hybridized with an anti-Bcl-2 monoclonal antibody (1:1000 dilution) or anti- $\beta$-actin monoclonal antibody (1:5000 dilution). Horse radish peroxidase-conjugated anti-rabbit/mouse IgG was used as the secondary antibody (1:5000 dilution).

\section{RT-PCR analysis}

The expression of the apoptotic-related genes was detected by RT-PCR. Total RNA was extracted from SH-SY5Y cells using Trizol reagent (Invitrogen). The integrity of RNA was examined by identifying intact $18 \mathrm{~s}$ and $28 \mathrm{~s}$ ribosomal RNA bands upon agarose gel electrophoresis. The purity and quantity were estimated by measuring the absorbance at $260 / 280 \mathrm{~nm}$ spectrophotometrically. RNA was reverse-transcribed into cDNA using M-MLV reverse transcriptase (Transgen Inc.). Quantitative real time PCR was performed using TansStartTM Green qPCR SuperMix (UDG) (Transgen Inc.) according to the following reaction conditions: $50^{\circ} \mathrm{C} 2 \mathrm{~min}$ (UDG Incubation), $95^{\circ} \mathrm{C} 10 \mathrm{~min}$ (UDG Inactivation), 40-45 cycles: $5 \sec 95^{\circ} \mathrm{C}, 15 \sec 55^{\circ} \mathrm{C}$ (according to different primers), and $10 \mathrm{sec} 72^{\circ} \mathrm{C}$. The collected data were analyzed using Rotor-Gene 6000 Series Software 1.7 (Qiagen, Valencia, CA, USA). Normal RT-PCR was performed using Taq DNA Polymerase (Transgen Inc.) and detected by gel electrophoresis. The PCR primers were designed by Primerpremier 5.0 software and synthesized by Shanghai Sangon Inc. (Shanghai, China). The primers for $\mathrm{Bcl}-2$ were (TM: $55^{\circ} \mathrm{C}$ ), forward: $5^{\prime}$-tgtgtggagagcgtcaacag-3' and reverse: $5^{\prime}$-cagacatgcacctacccagc-3'; for 18 s $R N A$ (TM: $55^{\circ} \mathrm{C}$ ), forward: $5^{\prime}$-cagccacccgagattgagca- $3^{\prime}$ and reverse: $5^{\prime}$-tagtagcgacgggcggtgtg- $3^{\prime}$; for $P 53$ (TM: $60^{\circ} \mathrm{C}$ ), forward: $5^{\prime}$-acagctttgaggtgcgtgttt $-3^{\prime}$ and reverse: $5^{\prime}-$ ccctttcttgcggagattctct- $3^{\prime}$; for caspase 3 (TM: $53^{\circ} \mathrm{C}$ ), forward: $5^{\prime}$-gaaattgtggaattgatgcgtga- $3^{\prime}$ and reverse: $5^{\prime}$-ctacaacgatcccctctgaaaaa- $3^{\prime}$; for caspase 9 (TM: $53^{\circ} \mathrm{C}$ ), forward: $5^{\prime}$-cttcgtttctgcgaactaacagg-3' and reverse: $5^{\prime}$ gcaccactggggtaaggttt- $3^{\prime}$; for $\beta$-actin (TM: $60^{\circ} \mathrm{C}$ ), forward: $5^{\prime}$-catgtacgttgctatccaggc- $3^{\prime}$ and reverse: $5^{\prime}$ ctccttaatgtcacgcacgat-3'.

\section{Assay for SOD, GSHPx and catalase activity}

SH-SY5Y cells were harvested and then lysed using cell lysis solution (Beyotime Institute of Biotechnology,
Jiangsu, China). Total protein concentration was quantified using the BCA Protein Assay Kit (Thermo Fisher Scientific Inc., Boston, MA, USA). The activity of SOD was determined using the total SOD assay kit with WST-1. The activities of GSHPx and catalase were determined using the cellular glutathione peroxidase assay kit and catalase assay kit according to the manufacturers' instructions.

\section{Statistical analysis}

Each experiment was repeated at least three times and results were expressed as the mean \pm standard deviation (SD). Analysis of variance was carried out using SPSS 11.0 (SPSS, Chicago, IL, USA). Values of $P<0.05$ were considered statistically significant.

\section{Results}

Geniposide, an active ingredient of TLJN, rescues the viability of SH-SY5Y cells treated with formaldehyde

TLJN preparation is clinically efficacious in the treatment of ischemic cerebral stroke and dementia $[14,17]$. In previous studies, we identified that TLJN has neuroprotective effects on ischemia/reperfusioninjured neurons and brain microvascular endothelial cells $[14,18]$. In this study, we investigated whether TLJN had a neuroprotective effect on formaldehydeinjured cells. SH-SY5Y cells (plated at $1 \times 10^{4}$ ) were grown in serum-free DMEM in the presence of $0.12 \mathrm{mM}$ formaldehyde supplemented with TLJN, geniposide or ginsenoside $\mathrm{Rg} 1$, to monitor changes in cell viability using CCK-8. As shown in Figure 2A, the relative viability of cells following formaldehyde treatment significantly decreased to $56.5 \%$ after a $24 \mathrm{~h}$ incubation when compared with the control $(100 \%$ viability) in the absence of formaldehyde $(P<0.05)$. However, in the presence of TLJN, cell viability was maintained at control levels, indicating its ability to rescue SH-SY5Y cells from formaldehyde injury.

As described previously [17], the effective components of TLJN are geniposide and ginsenoside Rg1. First, geniposide was employed to protect the cells in the presence of formaldehyde. The viability of cells supplemented with both formaldehyde and geniposide was significantly higher than that with formaldehyde alone $(P<0.05$, Figure 2A). Treatment with different concentrations of geniposide $(2.5,25,100$ and $250 \mu \mathrm{M})$ revealed that $25 \mu \mathrm{M}$ (or higher concentrations) of geniposide significantly elevated cell viability from $39.3 \%$ to $57.6 \%(P<0.05$, Figure $2 \mathrm{~B})$. Second, the protective effect of ginsenoside Rg1 on cells was tested under the same conditions. In contrast, ginsenoside Rg1 could not significantly rescue the viability of cells following formaldehyde treatment (Figure 2A). 


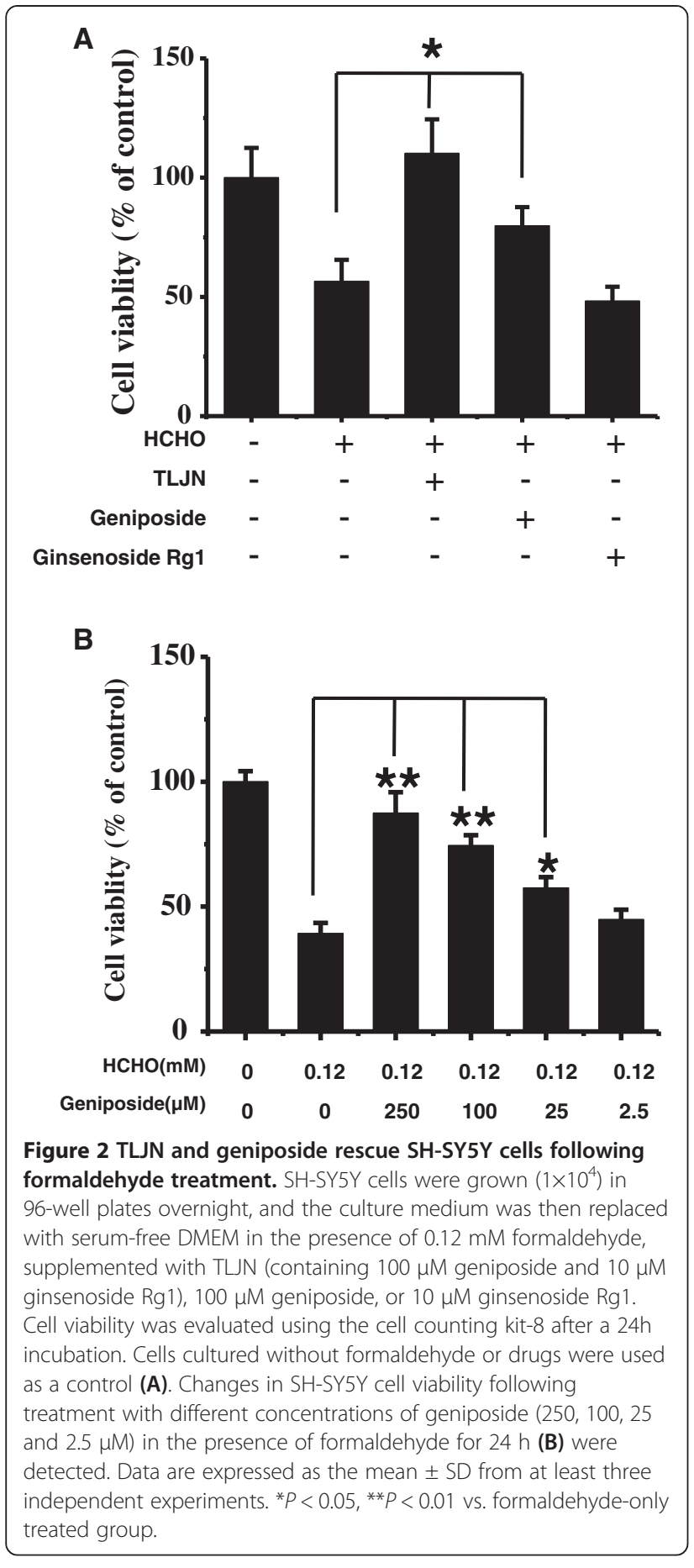

Geniposide rescues the morphology of SH-SY5Y cells in the presence of formaldehyde

Changes in cell morphology were also observed by laser scanning confocal microscopy at different time intervals following incubation (Figure 3). As shown in Figure 3E, SH-SY5Y cells treated with formaldehyde for $6 \mathrm{~h}$ shrank considerably when compared with the control (Figure 3A). This adverse effect of formaldehyde on cell growth was also observed at 12 and $24 \mathrm{~h}$ (Figure 3J and 3O). Cell morphological changes at $6 \mathrm{~h}$ were not significantly rescued in the presence of TLJN, geniposide or ginsenoside $\operatorname{Rg} 1$ when compared with formaldehyde treatment alone (Figure 3B, C, and D), suggesting that they did not exert a significant protective effect on cell growth at this early time point. Surprisingly, when cells were left for $12 \mathrm{~h}$, the shape of SH-SY5Y cells incubated with formaldehyde plus TLJN appeared to be much healthier than the formaldehyde-treated only group (Figure 3G to 3J). A similar effect was found in cells supplemented with geniposide (Figure $3 \mathrm{H}$ ). However, there was no significant difference between formaldehyde treatment and formaldehyde plus ginsenoside $\operatorname{Rg} 1$ treatment (Figure 3J to 3I). These results indicate that geniposide is the key component of TLJN that protects cells from the adverse effects of formaldehyde.

The numbers of surviving cells were also monitored in our study (Figure 3P). Formaldehyde treatment significantly decreased cell number at 12 and $24 \mathrm{~h}$, revealing its neurotoxic effect $(P<0.01)$. TLJN and geniposide significantly rescued the number of SH-SY5Y cells treated with formaldehyde at both 12 and $24 \mathrm{~h}$ $(P<0.01)$, indicating that geniposide but not ginsenoside Rg1 is able to rescue the viability of formaldehyde-injured SH-SY5Y cells under our experimental conditions. The protective effect of ginsenoside Rg1 on cellular morphology and cell number could not be detected.

We were next concerned with why geniposide can rescue formaldehyde-treated SH-SY5Y cells. First, HPLC was used to measure changes in the concentrations of formaldehyde in the cell culture medium. The results showed that the residual content of formaldehyde decreased by $20 \%$ in the presence of $25 \mu \mathrm{M}$ geniposide $(P<0.05$, Figure $4 \mathrm{~A})$. We also confirmed that at the concentrations used in the experiments, geniposide, ginsenoside Rg1, and TLJN showed no cytotoxicity to SH-SY5Y cells (Figure 4B). Overall, these results suggest that geniposide rescues formaldehyde-treated cells at least through its capability of decreasing formaldehyde levels. Thus, we next explored the mechanism of this protective effect of geniposide on SH-SY5Y cells.

\section{Protection of SH-SY5Y cells is not caused by a direct interaction of geniposide with formaldehyde in the culture medium}

Because both geniposide and formaldehyde were added to SH-SY5Y cells at the same time, and it was shown that geniposide decreased cytotoxicity following formaldehyde treatment, we could not exclude the possibility that geniposide directly interacted with formaldehyde and then rescued the viability of cells. Therefore, in the following experiment we added geniposide to the cell culture medium before cells 


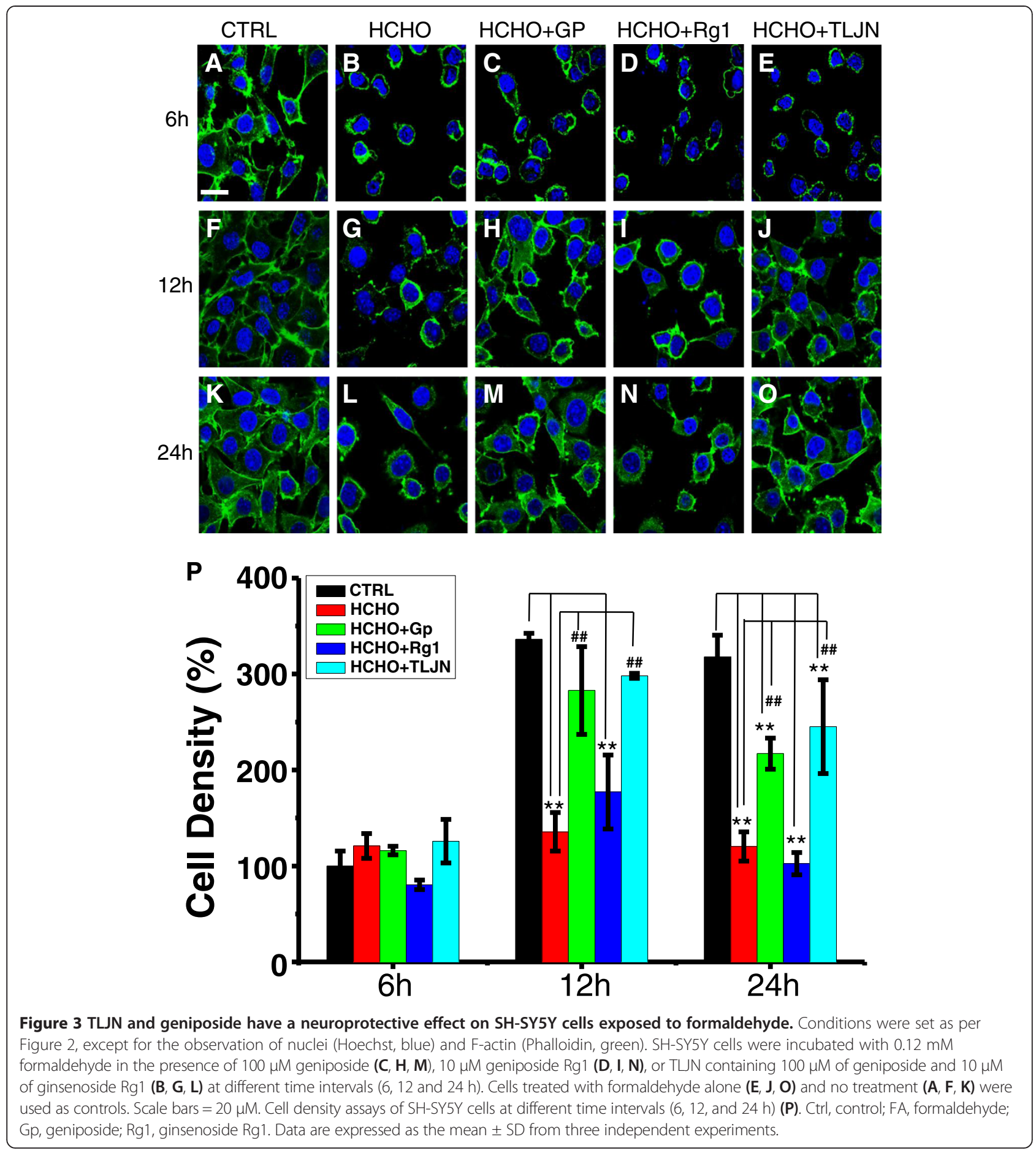

were treated with formaldehyde. Geniposide was removed after $12 \mathrm{~h}$ incubation with SH-SY5Y cells and then geniposide-treated cells were incubated with $0.12 \mathrm{mM}$ formaldehyde for another $12 \mathrm{~h}$. As shown by the CCK-8 assay (Figure 5A), cell viability of the geniposide-pretreated group was significantly higher $(P<0.01)$ than the formaldehyde alone treated group. Geniposide $(25 \mu \mathrm{M})$ increased the viability of cells from $62.1 \%$ to $80.2 \%$, similar to that of 100 and $250 \mu \mathrm{M}$ geniposide.

On the other hand, we treated cells with $0.12 \mathrm{mM}$ formaldehyde for $6 \mathrm{~h}$ first, and then incubated cells with geniposide or both geniposide and formaldehyde for $24 \mathrm{~h}$. Results from the CCK-8 assay demonstrated that geniposide could improve viability following formaldehyde injury under either condition (Figure 5B). 


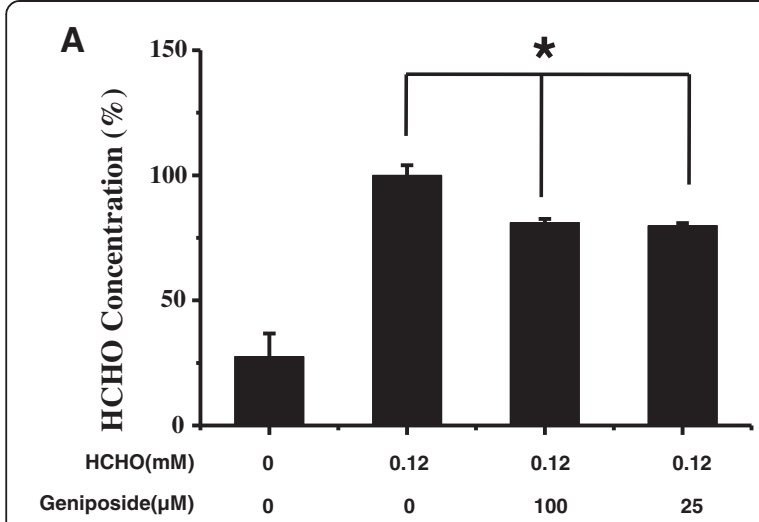

\section{B}

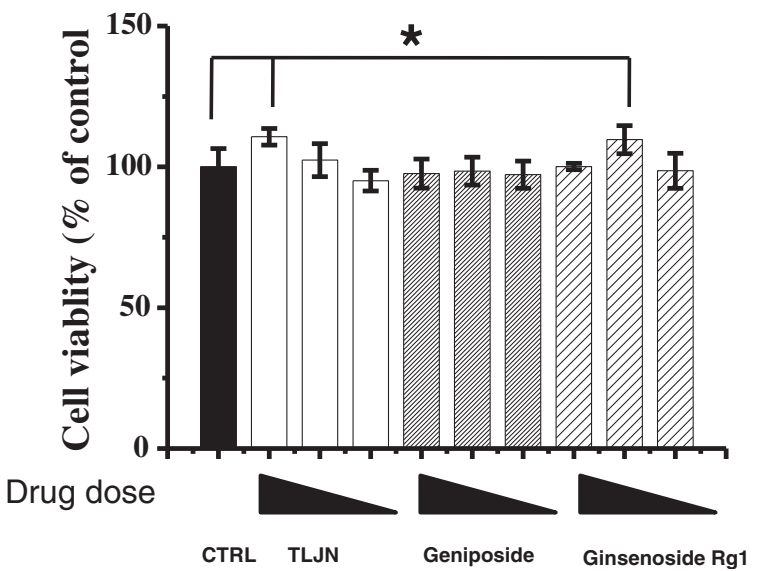

Figure 4 Changes in formaldehyde levels in culture medium and cell viability in the presence of geniposide. Decreases in formaldehyde concentrations in the medium of cells treated with geniposide $(100 \mu \mathrm{M}$ and $25 \mu \mathrm{M})$ for $24 \mathrm{~h}$ were detected by HPLC when compared with the formaldehyde-only group (control; $\mathbf{A}$ ). Changes in SH-SY5Y cell viability in the presence of TLJN, geniposide, or ginsenoside $\mathrm{Rg} 1$ at different concentrations $(250 \mu \mathrm{M}$ $100 \mu \mathrm{M}$ and $25 \mu \mathrm{M} ; \mathbf{B}$ ). Data are expressed as the mean $\pm \mathrm{SD}$ from at least three independent experiments. ${ }^{*} P<0.05$, ${ }^{* *} P<0.01$ vs. the group treated with formaldehyde alone.

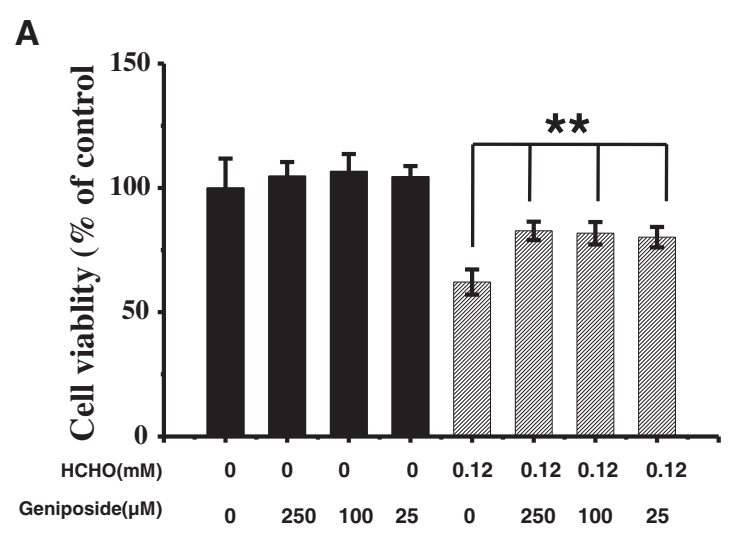

B

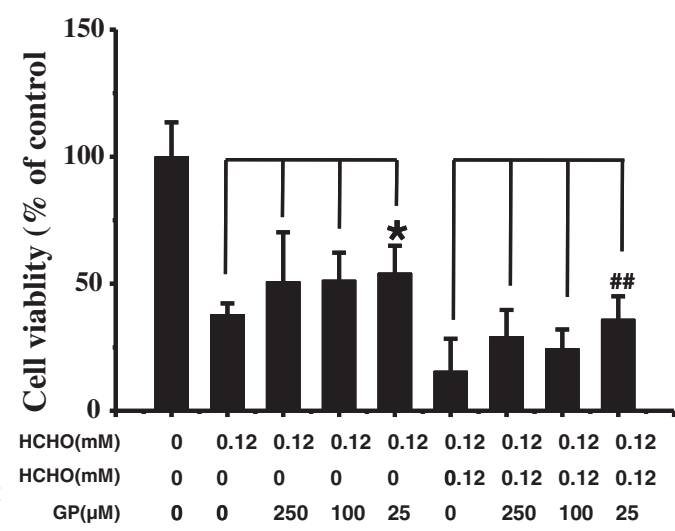

Figure 5 Geniposide protects SH-SY5Y cells from formaldehyde injury. Conditions for the treatment of cells were as described in Figure 2, except that SH-SY5Y cells were first incubated with different concentrations of geniposide overnight, followed by treatment with formaldehyde for $12 \mathrm{~h}$. The viability of cells was evaluated using the cell counting kit-8 (A). By contrast, cells were first exposed to formaldehyde overnight (conditions referred to in Figure 2), and then the medium was replaced with geniposide or both geniposide and formaldehyde for $24 \mathrm{~h}$, followed by measurement of cell vitality (B). Gp, geniposide. Data are expressed as the mean $\pm S D$ from three independent experiments. ${ }^{*} P<0.05$, vs. the group treated with formaldehyde alone.
The addition of $25 \mu \mathrm{M}$ geniposide to formaldehyde-injured cells increased their viability from $37.9 \%$ to $54.2 \%$ $(P<0.05)$. Viability increased from $15.6 \%$ to $36.1 \%$ in cells pretreated with formaldehyde for $6 \mathrm{~h}$ and in cells exposed to formaldehyde for $24 \mathrm{~h}$ following addition of geniposide $(P<0.01)$. This demonstrates that protection of SH-SY5Y cells by geniposide is not because of a direct interaction of geniposide with formaldehyde, but because of the activation of related cellular pathways.

\section{Geniposide suppresses apoptosis of SH-SY5Y cells in the presence of formaldehyde}

To determine how geniposide protects cells from formaldehyde toxicity, we first monitored the rate of apoptosis after treatment. SH-SY5Y cells (plated at $1 \times 10^{6}$ ) were grown in $60 \mathrm{~mm}$ plates overnight. Culture medium was then replaced with serumfree DMEM containing $0.12 \mathrm{mM}$ formaldehyde supplemented with 25 or $100 \mu \mathrm{M}$ geniposide for 24 h. Flow cytometry revealed that $5.82 \%$ of nontreated SH-SY5Y cells were apoptotic (Figure 6A). Incubation with $100 \mu \mathrm{M}$ geniposide (Figure 6B) could suppress formaldehyde-induced apoptosis of SH-SY5Y cells with the percentage of apoptotic cells decreasing from $12.15 \%$ to $5.25 \%$ when compared with formaldehyde-only treated cells (Figure 6C), indicating the inhibitory effect of geniposide on apoptosis. 

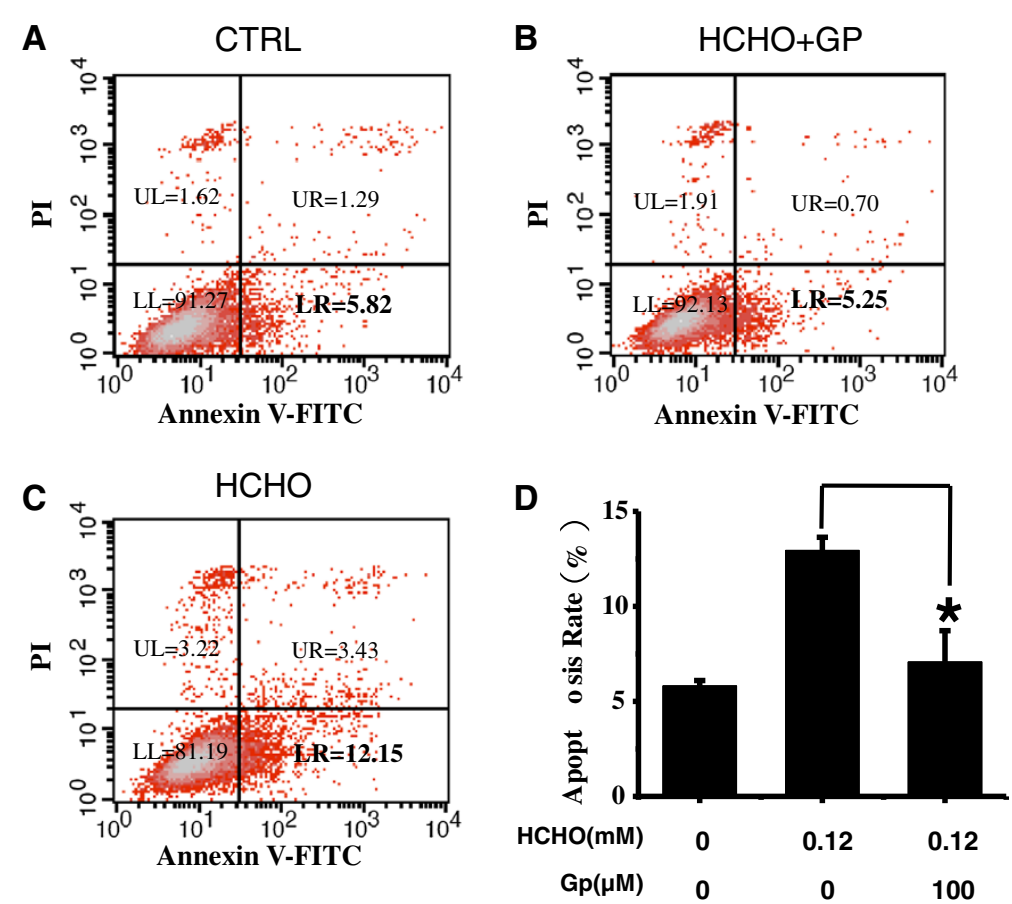

Figure 6 Geniposide suppresses apoptosis of SH-SY5Y cells following formaldehyde treatment. SH-SY5Y cells (A) were treated with $0.12 \mathrm{mM}$ formaldehyde in the presence (B) or absence of $100 \mu \mathrm{M}$ geniposide (C) for $24 \mathrm{~h}$, and then the rate of apoptosis was detected by flow cytometry. Geniposide suppressed SH-SY5Y cell apoptosis following formaldehyde treatment as indicated. The percentages of apoptotic SH-SY5Y cells (D) were analyzed. Data are expressed as the mean \pm SD from three independent experiments. ${ }^{*} P<0.05$, vs. the group incubated with formaldehyde alone. The figures $(\mathbf{A}, \mathbf{B}, \mathbf{C})$ are representative of three independent experiments.

Geniposide regulates apoptotic-related gene expression $\mathrm{Bcl}-2$ is the founding member of the $\mathrm{Bcl}-2$ family of apoptosis regulator proteins [19-21]. Thus, we investigated the changes in $\mathrm{Bcl}-2 \mathrm{mRNA}$ and protein expression. Our results showed that treatment of SH-SY5Y cells with formaldehyde induced a robust decrease in both $\mathrm{Bcl}-2$
mRNA and protein levels, followed by an increase in apoptotic cell death when cells were incubated with formaldehyde. However, treatment with different concentrations of geniposide $(25 \mu \mathrm{M}$ and $100 \mu \mathrm{M})$ was able to rescue levels of both $\mathrm{Bcl}-2$ mRNA (Figure 7A) and protein (Figure $7 \mathrm{~B}$ ) in the presence of formaldehyde. The
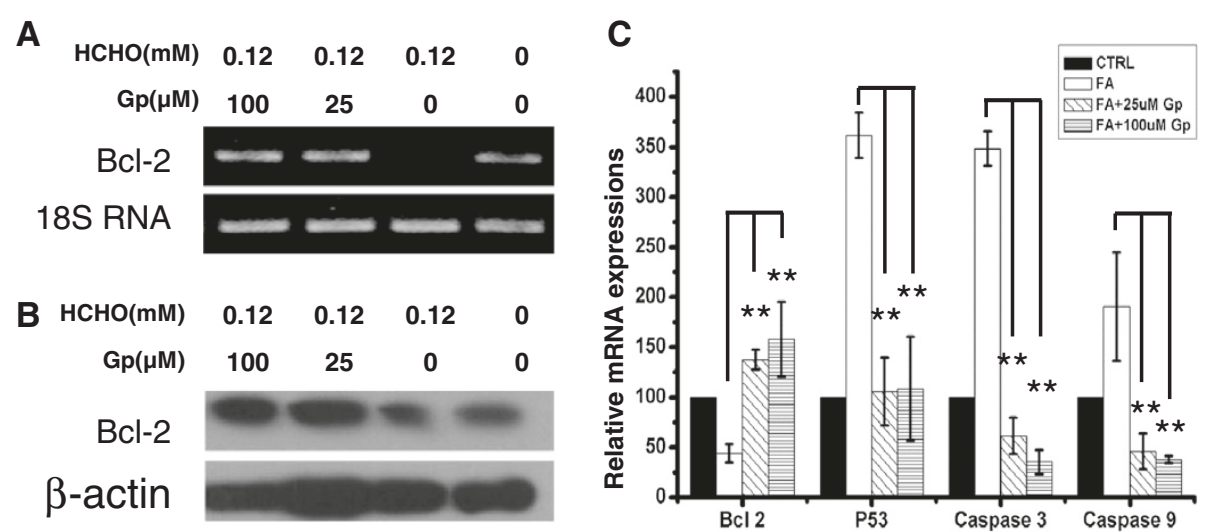

Figure 7 Geniposide regulates apoptotic-related genes expressions. Geniposide was able to regulate not only mRNA levels (A) but also protein levels of BCl-2 (B) to antagonize formaldehyde-induced SH-SY5Y cell impairment. SH-SY5Y cells were incubated with formaldehyde and geniposide for $24 \mathrm{~h}$. The expression of BCl-2, P53, caspase 3 and caspase 9 mRNA were measured by quantitative real time PCR (C). Treatment conditions were as described in Figure 2. Cells treated with formaldehyde alone and those with no treatment were used as positive and negative controls, respectively. Gp, geniposide. Data are expressed as the mean \pm SD from three independent experiments. ${ }^{*} P<0.05$, vs. the group treated with formaldehyde alone. The Gel electrophoresis is representative of three independent experiments. 
expression of $\mathrm{Bcl}-2$ mRNA decreased by $56.1 \%$ after exposure to formaldehyde, but treatment with geniposide markedly increased the expression of $\mathrm{Bcl}-2$ from $213.2 \%$ (25 $\mu \mathrm{M}$ geniposide) to $259.3 \%$ (100 $\mu \mathrm{M}$ geniposide). We also measured the expressions of P53, caspase 3 and caspase 9 mRNA by quantitative real time PCR. P53 is a key modulator of the cellular stress response, and activation of P53 can trigger apoptosis in many cell types including neurons [22]. Caspases play essential roles in apoptosis and caspase 3 is a key executer of apoptosis, whose activation is mediated by the initiator caspases, such as caspase 9 [23]. The expression of P53, caspase 3 and caspase 9 mRNA increased sharply by $261.5 \%, 248.2 \%$ and $90.5 \%$, respectively, in the formaldehyde-treated group. In the geniposide-treated group, the expression of these genes decreased markedly by $70.7 \%$ (P53), $82.3 \%$ (caspase 3) and $75.8 \%$ (caspase 9) after $25 \mu \mathrm{M}$ geniposide treatment and by $70.0 \%$ (P53), $89.8 \%$ (caspase 3) and $80.1 \%$ (caspase 9) after $100 \mu \mathrm{M}$ geniposide treatment. These results suggest that $B c l-2, P 53$, caspase 3 and caspase 9 are involved in the protective effect of geniposide following formaldehyde injury of SH-SY5Y cells.

\section{Geniposide increases the activity of SOD and GSHPx}

The generation of excess levels of reactive oxygen species (ROS) is important for the activation of apoptosis. SOD, GSHPx and catalase play a critical antioxidative role in tissues and organs [24]. Therefore, we next tested the activity of SOD, GSHPx and catalase in cells. As shown in Figure $8 \mathrm{~A}$ and $8 \mathrm{~B}$, after exposure to formaldehyde, the activity of SOD and GSHPx decreased significantly $(P<0.05)$ when compared with the control. In contrast, treatment with $100 \mu \mathrm{M}$ geniposide markedly increased the activity of SOD (from $63.7 \%$ to $107.2 \%, P<0.01$ ) and GSHPx (from $81.5 \%$ to $127.5 \%, P<0.01$ ) when compared with DMSO-incubated cells under our experimental conditions. The activity of catalase (Figure 8C) did not differ among the four experimental groups. This result demonstrates that geniposide improves the activity of SOD and GSHPx leading to suppression of apoptosis of $\mathrm{SH}-\mathrm{SY} 5 \mathrm{Y}$ cells in the presence of formaldehyde.

\section{Discussion}

An increase in the concentration of endogenous formaldehyde (in blood and urine) has been found to correlate with an increase in age [7]. The concentration of hippocampal formaldehyde in AD patients is significantly higher than those of healthy seniors [7,25]. There is a certain amount of formaldehyde existing in the body, which is produced from several sources, such as the reaction of malondialdehyde with protein [20] and the methylation of DNA $[5,26]$. The cytotoxic mechanisms of formaldehyde have been studied in several experimental models. Formaldehyde is extremely reactive, cross-linking

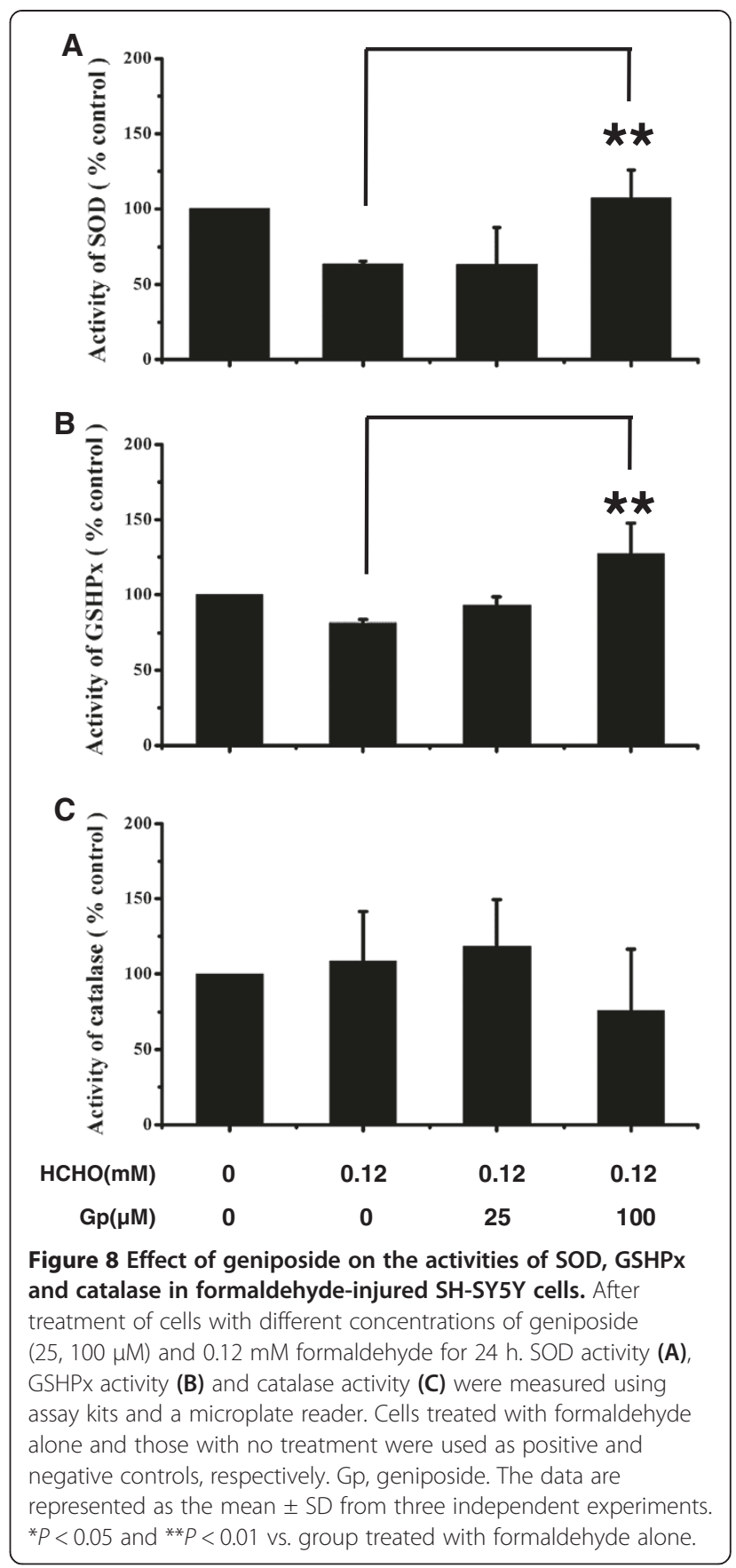

with proteins and with single stranded DNA, causing cellular dysfunction and even apoptosis [27]. Excess formaldehyde can also lead to endoplasmic reticulum stress and oxidative stress [28], which has been termed 'formaldehyde stress' [5]. Formaldehyde can also induce toxicity in neurons and astrocytes by multiple means, and in astrocytes, decreasing glutamate transporter expression, and inhibit glutamate uptake [29]. Moreover, formaldehyde is neurotoxic, and chronic 
overdosing increases the risk of $\mathrm{AD}$ and other related neurological disorders [30].

In our study, we found that TLJN could attenuate formaldehyde-induced neurotoxicity in cultured SH-SY5Y cells. Geniposide and ginsenoside Rg1 are the two main ingredients of TLJN [14]. In a previous study, we have shown that geniposide has a significant neuroprotective effect by blocking the progressive cascade that leads to cerebral ischemic injury and improving the expression of neurotrophic factors [13]. Moreover, ginsenoside Rg1 significantly stimulates neurite outgrowth of PC12 cells in the absence of nerve growth factor [31]. The present study indicates that geniposide is also able to attenuate formaldehyde-induced neurotoxicity, but that ginsenoside $\operatorname{Rg} 1$ is ineffective under these conditions. TLJN was more effective in neuroprotection than geniposide, exhibiting some integrated effects of geniposide and ginsenoside Rg1. Moreover, geniposide attenuated neurotoxicity in a dose-dependent pattern. Treatment with $25 \mu \mathrm{mol} / \mathrm{L}$ geniposide could increase cell viability from $39.3 \%$ to $57.6 \%$ (Figure $2 \mathrm{~B}$ ), with cell viability increasing markedly with increasing dosage.

In addition to cell viability, the morphology and cell number of SH-SY5Y cells following formaldehyde injury was rescued in the presence of geniposide and TLJN. While the protective effect of ginsenoside Rg1 on cellular morphology and cell number could not be detected. Furthermore, the concentration of formaldehyde in the cell culture medium significantly decreased after treatment with geniposide. Incubation with $25 \mu \mathrm{mol} / \mathrm{L}$ geniposide reduced the content of formaldehyde in the medium from $100 \%$ to $79.8 \%$. This result indicates that there could be a direct interaction between geniposide and formaldehyde. However, this may also be because of the presence of several formaldehyde metabolic enzymes, such as alcohol dehydrogenase I, alcohol dehydrogenase III, formaldehyde dehydrogenase and aldehyde dehydrogenase 2 [1,5]. Therefore, the reason for the reduction in formaldehyde content may be because geniposide can upregulate the activity of formaldehyde metabolic enzymes or increase the metabolism of formaldehyde by healthy cells. We have tested whether geniposide could protect SH-SY5Y cells from formaldehyde injury following the addition of geniposide and formaldehyde to the cell culture medium in different orders. As shown in Figure 5, geniposide added to cultures before, at the same time, or after cells were exposed to formaldehyde resulted in an increase in cell viability. These results indicate that both possibilities, namely geniposide reacting with formaldehyde and protecting cells directly, are plausible. However, dosedependent effects could not be observed under these experimental conditions. The lack of a dose-dependent effect suggests that $25 \mu \mathrm{M}$ geniposide may already cause a maximal effect.
Geniposide, the active constituent of Gardenia jasminoides, which is widely used in Chinese traditional medicine, has been shown to have a neuroprotective effect against neuronal apoptosis induced by $A \beta$, $\mathrm{CoCl}_{2}$, and $\mathrm{H}_{2} \mathrm{O}_{2}$ [19,32,33]. Our study showed that geniposide could also protect against neuronal apoptosis induced by formaldehyde. $\mathrm{Bcl}-2$ is an antiapoptotic oncoprotein that can promote cell survival [24]. P53 is a key modulator of cellular stress responses, and its activation triggers apoptosis in many cell types including neurons [22]. Caspases play essential roles in apoptosis and caspase 3 is a key executer of apoptosis, whose activation is mediated by the initiator caspases, such as caspase 9 [23]. Herein, geniposide inhibited cell apoptosis through modulation of $\mathrm{Bcl}-2, \mathrm{P} 53$, caspase 3 and caspase 9 mRNA levels. Oxidative stress is one of the major events that occur during neurological diseases such as $\mathrm{AD}$ [1]. In addition, oxidative stress is one of the main mechanisms for inducing apoptotic cell death, in which levels of ROS are upregulated [19]. Cells are susceptible to oxidative stress-induced apoptosis when levels of intracellular antioxidants are downregulated. SOD, GSHPx and catalase are important antioxidant

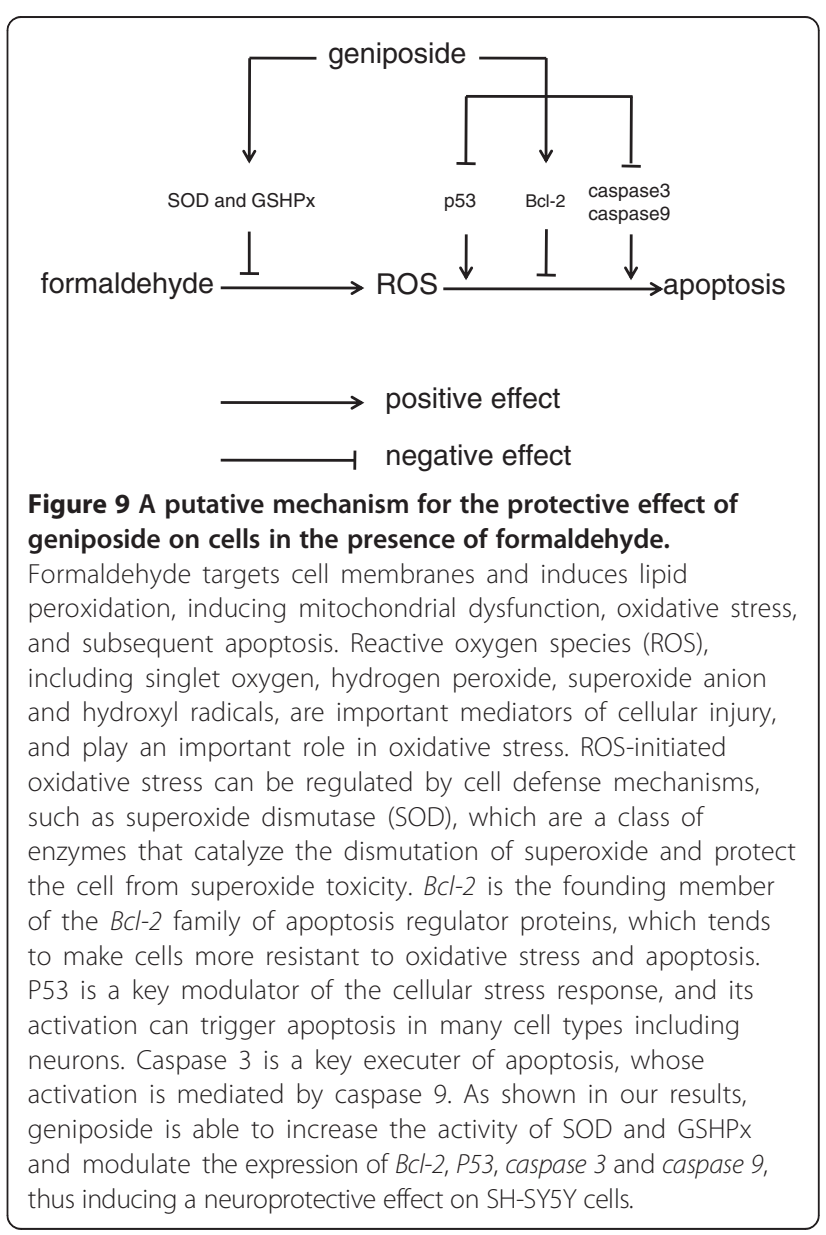


defenses in nearly all cells exposed to oxygen free radicals. In our study, the activity of SOD and GSHPx in SH-SY5Y cells decreased significantly when exposed to formaldehyde. However, treatment with $100 \mu \mathrm{mol} / \mathrm{L}$ geniposide increased the activity of SOD from $63.7 \%$ (formaldehyde alone) to $107.2 \%$ and that of GSHPx from $81.5 \%$ to $127.5 \%(P<0.01)$. Therefore, we propose that geniposide inhibits apoptotic cell death following formaldehyde injury by increasing the antioxidative and antiapoptotic capacity of cells (Figure 9).

\section{Conclusions}

In the presence of TLJN, the viability of formaldehydetreated SH-SY5Y cells remarkably recovered. In addition, the morphology of cells was rescued by TLJN and geniposide, an effective ingredient of TLJN. The activity of intracellular antioxidants (SOD and GSHPx), as well as mRNA and protein levels of the antiapoptotic gene $\mathrm{Bcl}$-2 were upregulated after the addition of geniposide. The expression of the apoptotic-related gene - P53, apoptotic executer - caspase 3 and apoptotic initiator - caspase 9 were downregulated after geniposide treatment. Our results indicate that geniposide can protect SH-SY5Y cells against formaldehyde stress by modulating the expressions of $\mathrm{Bcl}-2, \mathrm{P} 53$, caspase 3 and caspase 9, and increasing the activity of intracellular SOD and GSHPx.

\section{Abbreviations}

AD: Alzheimer's disease; TLJN: TongLuoJiuNao; TCM: Traditional Chinese medicine; GLP-1R: Glucagon-like peptide 1 receptor; SOD: Superoxide dismutase; DMEM: Dulbecco's modified eagle medium; SD: Standard deviation; ROS: Reactive oxygen species; GSHPx: Glutathione peroxidase.

\section{Competing interests}

The authors declare that they have no competing interests.

\section{Authors' contributions}

PS, JC and MS performed the studies and analyzed the data. JL, WM and KL evaluated the data and performed the analysis. YM, JL, FW and YL conceived the study together and helped draft the manuscript. $\mathrm{RH}$ and $\mathrm{QH}$ conceived the project, and wrote and revised the manuscript. All authors have read and approved the final manuscript.

\section{Acknowledgements}

This study was supported by grants from the National Natural Science Foundation (81072901), New Teacher Fund for Doctor Station, Ministry of Education (20120013110013) and the 973 Program (2010CB912303; 2012CB911004). The authors have no conflict of interest to disclose.

\footnotetext{
Author details

${ }^{1} S c h o o l$ of Preclinical Medicine, Beijing University of Chinese Medicine, 11 Bei San Huan Dong Road, Chaoyang District, Beijing 100029, China. ${ }^{2}$ State Key Laboratory of Brain and Cognitive Science, Institute of Biophysics, Chinese Academy of Sciences, 15 Datun Road, Chaoyang District, Beijing 100101, China. ${ }^{3}$ School of Chinese Materia Medica, Beijing University of Chinese Medicine, 11 Bei San Huan Dong Road, Chaoyang District, Beijing 100029, China.
}

Received: 26 February 2013 Accepted: 26 June 2013

Published: 1 July 2013

\section{References}

1. Michel TM, Gsell W, Käsbauer L, Tatschner T, Sheldrick AJ, et al: Increased activity of mitochondrial aldehyde dehydrogenase (ALDH) in the putamen of individuals with Alzheimer's disease: a human postmortem study. J Alzheimers Dis 2010, 19(4):1295-1301.

2. Boomsma F, van den Meiracker AH, Winkel S, Aanstoot HJ, Batstra MR, et al: Circulating semicarbazide-sensitive amine oxidase is raised both in Type I (insulin-dependent), in Type II (non-insulin-dependent) diabetes mellitus and even in childhood Type I diabetes at first clinical diagnosis. Diabetologia 1999, 42(2):233-237.

3. Ivanova S, Botchkina Gl, Al-Abed Y, Meistrell M, Batliwalla F, et al: Cerebral ischemia enhances polyamine oxidation: Identification of enzymatically formed 3-aminopropanal as an endogenous mediator of neuronal and glial cell death. J Exp Med 1998, 188(2):327-340.

4. Yu PH: Involvement of cerebrovascular semicarbazide-sensitive amine oxidase in the pathogenesis of Alzheimer's disease and vascular dementia. Med Hypotheses 2001, 57(2):175-179.

5. He RQ, Lu J, Miao J: Formaldehyde stress. Sci China Life Sci 2010, 53(12):1399-1404

6. Kilburn $\mathrm{KH}$, Warshaw R, Thornton JC: Formaldehyde impairs memory, equilibrium, and dexterity in histology technicians - effects which persist for days after exposure. Arch Environ Health 1987, 42(2):117-120.

7. Tong ZQ, Zhang JL, Luo WH, Wang WS, Li FX, et al: Urine formaldehyde level is inversely correlated to mini mental state examination scores in senile dementia. Neurobio Aging 2011, 32(1):31-41.

8. Lu J, Miao JY, Pan R, He RQ: Formaldehyde-mediated Hyperphosphorylation Disturbs The interaction between Tau protein and DNA. Prog Biochem Biophys 2011, 38:1113-1120.

9. Nie CL, Wang XS, Liu Y, Perrett S: Amyloid-like aggregates of neuronal tau are induced by formaldehyde exposure and promote apoptosis of neuronal cells. BMC Neurosci 2007, 23:8-9.

10. Lu J, Miao JY, Su T, Liu Y, He RQ: Formaldehyde induces hyperphosphorylation and polymerization of Tau protein both in vitro and in vivo. Biochim Biophys Acta-General Subjects 2013, 1830(8):4102-4116.

11. Hua $Q, H e R Q$ : Effect of phosphorylation and aggregation on tau binding to DNA. Protein Pept Lett 2002, 9:349-357.

12. Chen K, Maley J, Yu PH: Potential implications of endogenous aldehydes in beta-amyloid misfolding, oligomerization and fibrillogenesis. J Neurochem 2006, 99(5):1413-1424

13. Si YC, Wu HX, Xu H, Niu X, Li PT: Tongluo Jiunao injection's effects on glutamic acid and expression of its NMDA receptor in cerebral cortical infarction in rat with cerebral ischemia. China J Trad Chi Med Pharm 2003, 18:466-467.

14. Hua Q, Qing XM, Li PT, Li WH, Hou JC, et al: Brain microvascular endothelial cells mediate neuroprotective effects on ischemia/ reperfusion neurons. J Ethnopharmacol 2010, 129(3):306-313.

15. Yin F, Liu JH, Zheng XX, Guo LX: GLP-1 receptor plays a critical role in geniposide-induced expression of heme oxygenase-1 in PC12 cells. Acta Pharmacol Sin 2010, 31(5):540-545.

16. Radad K, Gille G, Moldzio R, Saito H, Rausch WD: Ginsenosides Rb-1 and Rg (1) effects on mesencephalic dopaminergic cells stressed with glutamate. Brain Res 2004, 1021(1):41-53.

17. Liu Y, Hua Q, Lei HT, Li PT: Effect of Tong Luo Jiu Nao on A beta-degrading enzymes in AD rat brains. J Ethnopharmacol 2011, 137(2):1035-1046.

18. Li XJ, Hou JC, Sun P, Li PT, He RQ, et al: Neuroprotective effects of TongLuoJiuNao in neurons exposed to oxygen and glucose deprivation. J Ethnopharmacol 2012, 141(3):927-933.

19. Adams JM, Cory S: The Bcl-2 protein family: Arbiters of cell survival. Sci 1998, 281(5381):1322-1326.

20. Jomova K, Valko M: Advances in metal-induced oxidative stress and human disease. Toxicol 2011, 283(2-3):65-87.

21. Schmitz I, Kirchhoff S, Krammer PH: Regulation of death receptor-mediated apoptosis pathways. Int J Biochem Cell Biol 2000, 32(11-12):1123-1136.

22. Culmsee C, Mattson MP: p53 in neuronal apoptosis. Biochem Biophys Res Commun 2005, 331(3):761-777.

23. Khurana P, Ashraf QM, Mishra OP, Delivoria-Papadopoulos M: Effect of hypoxia on caspase- $3,-8$, and -9 activity and expression in the cerebral cortex of newborn piglets. Neurochem Res 2002, 27(9):931-938.

24. Liang W, Ge SH, Yang LH, Yang M, Ye ZX, et al: Ginsenosides Rb1 and Rg1 promote proliferation and expression of neurotrophic factors in primary Schwann cell cultures. Brain Res 2010, 1357:19-25. 
25. Tong ZQ, Han CS, Luo WH, Wang X, Li H, Luo HJ, Zhou J, Qi J, He RQ: Accumulated hippocampal formaldehyde induces age-dependent memory decline. Age (Dordr) 2013, 35(3):583-596.

26. Tong ZQ, Han CS, Luo WH, Li H, Luo HJ, Qiang M, Su T, Wu BB, Liu Y, Yang $X$, Wan Y, Cui DH, He RQ: Aging-associated excess formaldehyde leads to spatial memory deficits. Sci Rep 2013, 3:1807.

27. Williams CW, Lees-Haley PR: Research on chronic, low-level exposure to formaldehyde: implications for neuropsychological assessment. J Clin Psychol 1998, 54(6):851-862.

28. Li F, Yang Z, Lu Y, Wei Y, Wang J, et al: Malondialdehyde Suppresses Cerebral Function by Breaking Homeostasis between Excitation and Inhibition in Turtle. PLoS One 2010, 5(12):e15325.

29. Song MS, Baker GB, Dursun SM, Todd KG: The antidepressant phenelzine protects neurons and astrocytes against formaldehyde-induced toxicity. J Neurochem 2010, 114(5):1405-1413.

30. Wei Y, Miao JY, Liu Y: Endogenous and exogenous factors in Tau abnormal phosphorylation in early stage of Alzheimer's disease. Prog Biochem Biophys 2012, 39(8):778-784.

31. Rudakewich M, Ba F, Benishin CG: Neurotrophic and neuroprotective actions of ginsenosides $\mathrm{Rb}(1)$ and $\mathrm{Rg}(1)$. Planta Med 2001, 67(6):533-537.

32. Guo LX, Liu JH, Xia ZN: Geniposide inhibits $\mathrm{CoCl}_{2}$-induced $\mathrm{PC} 12$ cells death via the mitochondrial pathway. Chin Med J 2009, 122(23):2886-2892.

33. Liu JH, Yin F, Guo LX, Deng XH, Hu YH: Neuroprotection of geniposide against hydrogen peroxide induced $\mathrm{PC} 12$ cells injury: involvement of $\mathrm{PI} 3$ kinase signal pathway. Acta Pharmacol Sin 2009, 30(2):159-165.

doi:10.1186/1472-6882-13-152

Cite this article as: Sun et al: The protective effect of geniposide on human neuroblastoma cells in the presence of formaldehyde. $B M C$

Complementary and Alternative Medicine 2013 13:152.

\section{Submit your next manuscript to BioMed Central and take full advantage of:}

- Convenient online submission

- Thorough peer review

- No space constraints or color figure charges

- Immediate publication on acceptance

- Inclusion in PubMed, CAS, Scopus and Google Scholar

- Research which is freely available for redistribution 